GET

FILE='C: \Users \Admin_pc \Desktop \Honey \Honey SPSS Honey Data.sav' .

Warning \# 67. Command name: GET FILE

The document is already in use by another user or process. If you make

changes to the document they may overwrite changes made by others or your changes may be overwritten by others.

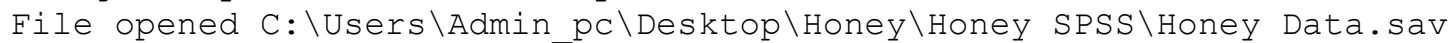
DATASET NAME DataSet1 WINDOW=FRONT.

DATASET ACTIVATE Dataset 1 .

DISPLAY DICTIONARY.

\title{
File Information
}

[DataSet1] C: \Users \Admin_pc \Desktop \Honey \Honey SPSS $\backslash$ Honey Data.sav

Variable Information

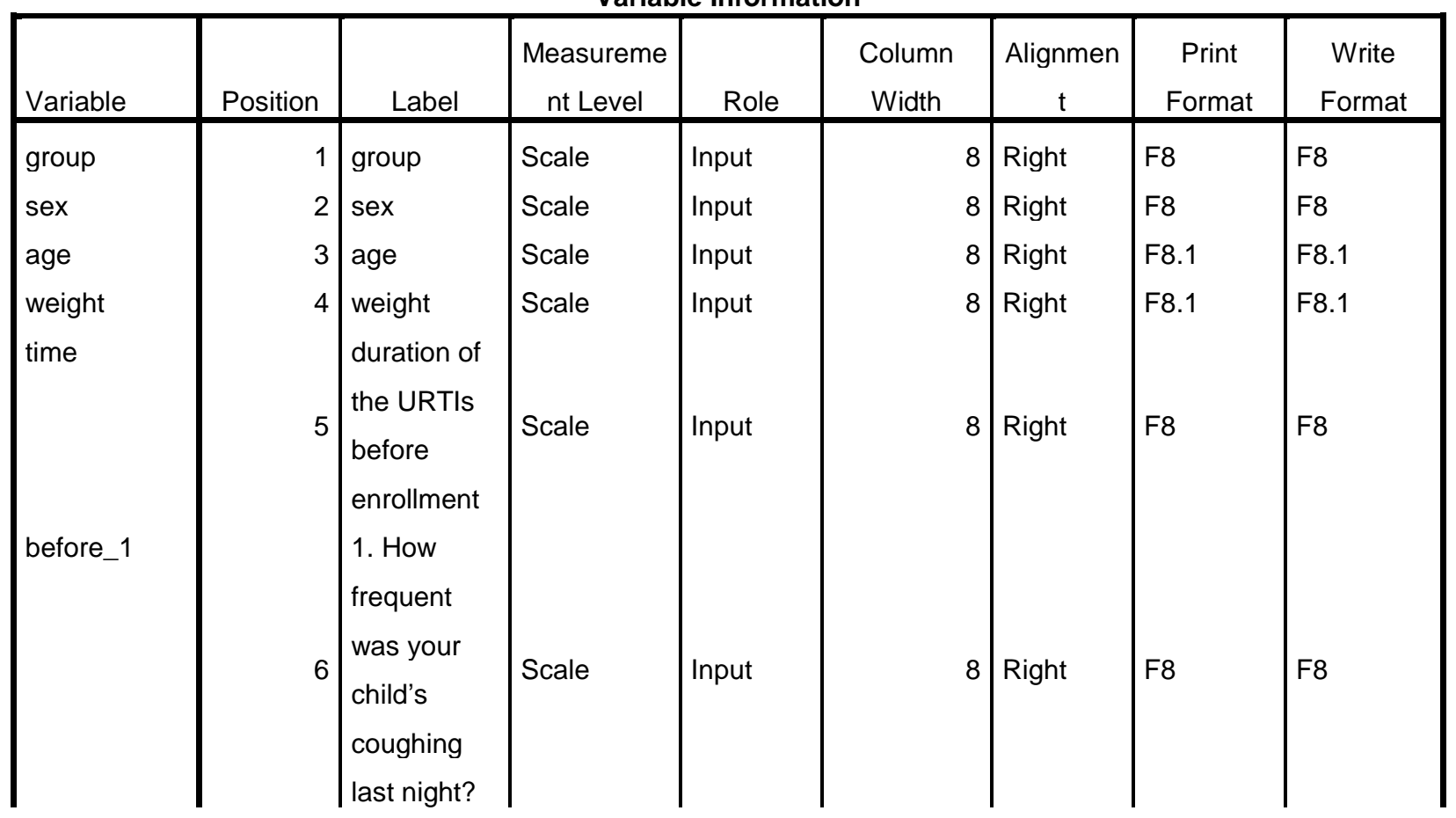




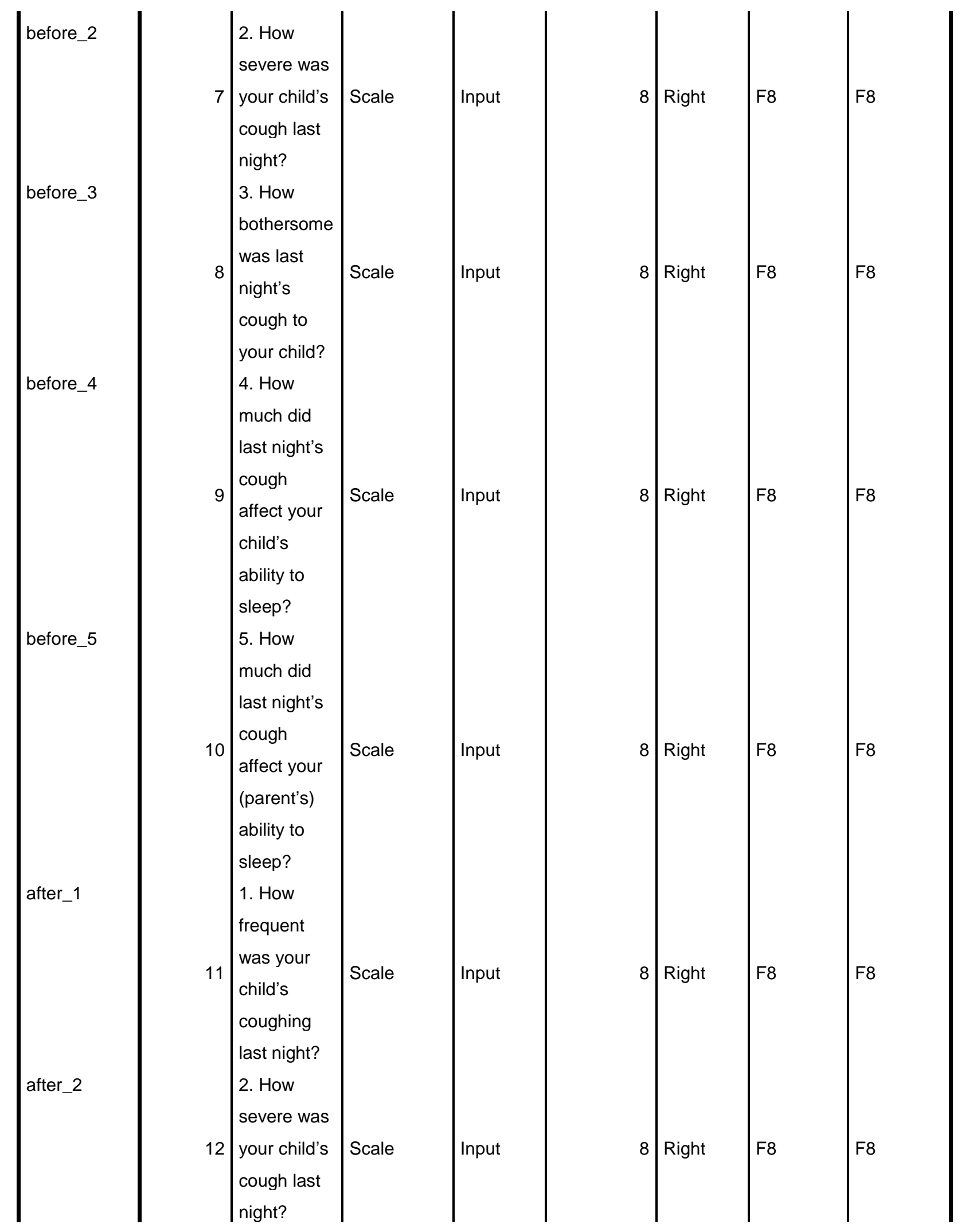




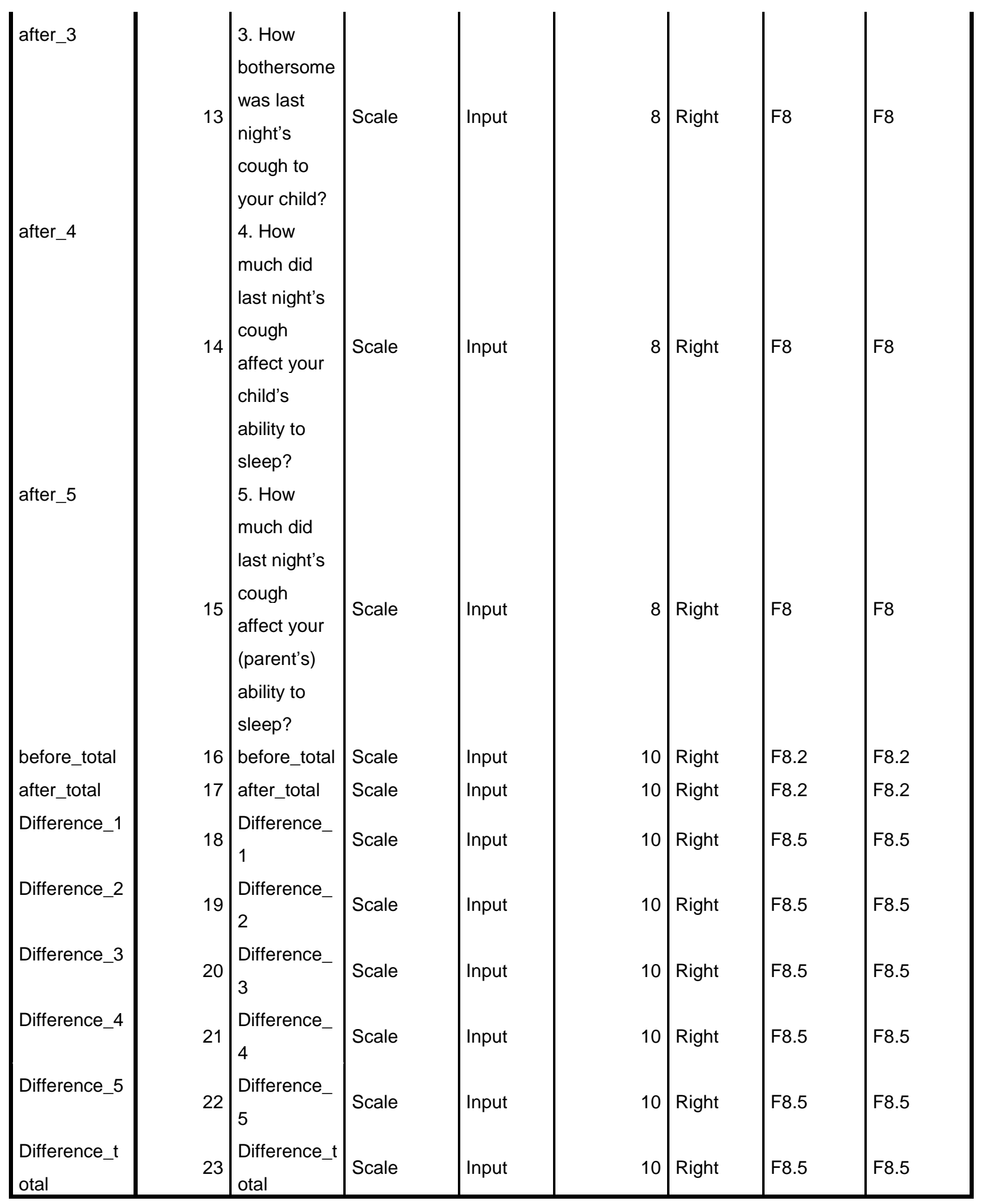

Variables in the working file 


\begin{tabular}{|ll|l|}
\hline \multicolumn{2}{|c|}{ Variable Values } \\
\hline Value & \multicolumn{1}{c|}{ Label } \\
\hline group & 1 & honey-Kimia \\
& 2 & Diphenhydramine \\
& 3 & honey_Shahd-eGolha \\
sex & 1 & boy \\
& 2 & girl \\
\hline
\end{tabular}

